\title{
Sponges of Posidonia oceanica meadows (Sardinia, W-Mediterranean Sea)*
}

\author{
A. Padiglia ${ }^{1-2}$, B. Cadeddu ${ }^{2}$, D. Demurtas ${ }^{2}$, M. Bertolino $^{1}$, R. Manconi ${ }^{2}$, R. Pronzato ${ }^{1}$ \\ ${ }^{1}$ University of Genoa - Dept. of Earth, Environment and Life Sciences \\ ${ }^{2}$ University of Sassari - Dept. of Science for Nature and Environmental Resources \\ *andreapadiglia@alice.it
}

Sponges are one of the main components of Mediterranean benthic ecosystems. Aim of this work was to perform a preliminary survey of conspicuous sponges in the Marine Protected Areas of Capo Caccia - Isola Piana and Asinara (North-Western Sardinia) harbouring wide Posidonia oceanica meadows. Specimens were photographed in vivo, collected along linear transects in shallow water by snorkeling and SCUBA diving, preserved (dry and/or ethanol) and identified at species level. Preliminary results show notable values of taxonomic richness when compared to previous papers confirming that $P$. oceanica meadows represent a suitable habitat for sponges. Some sponge species preferentially colonize rhizomes, others are found mainly in inter-mattes areas; only a few species are able to settle on leaves. Rhizomes offer a steady, permanent and shaded substratum, while leaves represent an unsteady substrate been smooth, short-lived, more exposed, and constantly moving. Sponges perform different key functional roles in the meadows:

a) they host diversified invertebrate associations providing also refuge for sciaphilous invertebrates and nursery for juveniles at body surface and within canals of the aquiferous system; $b$ ) they are able to recycle particulate and dissolved organic matter acting as biofilters (active filter feeders); c) they contribute to improve circulation by pumping activity in the water column producing microcurrents particulary effective in lentic conditions. On the other side, to live in the meadows is very advantageous for sponges, gaining protection against storm surges. However data suggest the need of continuous monitoring to assess the impact of invasive algae such as those belonging to the genus Caulerpa and contribute to shed light on the problem of diversity loss by alien species.

${ }^{*}$ Research funded in part by MPA Isola dell'Asinara, RAS-CRP60215 (Regione Autonoma Sardegna), Master\&Back (RAS) and Fondazione Banco di Sardegna 